\title{
Oral administration of morphine versus ibuprofen to manage postfracture pain in children: a randomized trial
}

\author{
Naveen Poonai MD, Gina Bhullar BSc, Kangrui Lin MD, Adam Papini MD, David Mainprize BSc, \\ Jocelyn Howard MD, John Teefy BSc, Michelle Bale BSc, Cindy Langford RN, Rodrick Lim MD, \\ Larry Stitt MSc, Michael J. Rieder MD PhD, Samina Ali MD
}

Competing interests: None declared.

This article has been peer reviewed.

Correspondence to: Naveen Poonai, naveen. poonai@1hsc.on.ca

CMAJ 2014. DOI:10.1503 /cmaj.140907

\begin{abstract}
Background: Recent warnings from Health Canada regarding codeine for children have led to increased use of nonsteroidal antiinflammatory drugs and morphine for common injuries such as fractures. Our objective was to determine whether morphine administered orally has superior efficacy to ibuprofen in fracture-related pain.
\end{abstract}

Methods: We used a parallel group, randomized, blinded superiority design. Children who presented to the emergency department with an uncomplicated extremity fracture were randomly assigned to receive either morphine $(0.5 \mathrm{mg} / \mathrm{kg}$ orally) or ibuprofen $(10 \mathrm{mg} / \mathrm{kg})$ for 24 hours after discharge. Our primary outcome was the change in pain score using the Faces Pain Scale - Revised (FPS-R). Participants were asked to record pain scores immediately before and 30 minutes after receiving each dose.

Results: We analyzed data from 66 participants in the morphine group and 68 participants in the ibuprofen group. For both morphine and ibuprofen, we found a reduction in pain scores (mean pre-post difference \pm stan- dard deviation for dose 1 : morphine $1.5 \pm 1.2$ ibuprofen $1.3 \pm 1.0$, between-group difference $[\delta] 0.2[95 \%$ confidence interval $(\mathrm{Cl})-0.2$ to 0.6 ]; dose 2 : morphine $1.3 \pm 1.3$, ibuprofen $1.3 \pm 0.9, \delta 0[95 \% \mathrm{Cl}-0.4$ to 0.4$]$; dose 3 : morphine $1.3 \pm 1.4$, ibuprofen $1.4 \pm 1.1, \delta-0.1$ [95\% Cl -0.7 to 0.4$]$; and dose 4: morphine 1.5 \pm 1.4 , ibuprofen $1.1 \pm 1.2, \delta 0.4[95 \% \mathrm{Cl}-0.2$ to 1.1]). We found no significant differences in the change in pain scores between morphine and ibuprofen between groups at any of the 4 time points $(p=0.6)$. Participants in the morphine group had significantly more adverse effects than those in the ibuprofen group $(56.1 \%$ v. $30.9 \%, p<0.01)$.

Interpretation: We found no significant difference in analgesic efficacy between orally administered morphine and ibuprofen. However, morphine was associated with a significantly greater number of adverse effects. Our results suggest that ibuprofen remains safe and effective for outpatient pain management in children with uncomplicated fractures. Trial registration: ClinicalTrials.gov, no. NCT01690780.
$\mathrm{T}$ here is ample evidence that analgesia is underused, ${ }^{1}$ underprescribed, ${ }^{2}$ delayed in its administration ${ }^{2}$ and suboptimally dosed ${ }^{3}$ in clinical settings. Children are particularly susceptible to suboptimal pain management ${ }^{4}$ and are less likely to receive opioid analgesia. ${ }^{5}$ Untreated pain in childhood has been reported to lead to short-term problems such as slower healing ${ }^{6}$ and to long-term issues such as anxiety, needle phobia, ${ }^{7}$ hyperesthesia ${ }^{8}$ and fear of medical care. ${ }^{9}$ The American Academy of Pediatrics has reaffirmed its advocacy for the appropriate use of analgesia for children with acute pain. ${ }^{10}$

Fractures constitute between $10 \%$ and $25 \%$ of all injuries. ${ }^{11}$ The most severe pain after an injury occurs within the first 48 hours, with more than $80 \%$ of children showing compromise in at least 1 functional area. ${ }^{12}$ Low rates of analgesia have been reported after discharge from hospital. ${ }^{13}$ A recently improved understanding of the pharmacogenomics of codeine has raised significant concerns about its safety, ${ }^{14,15}$ and has led to a Food and Drug Administration boxed warning ${ }^{16}$ and a Health Canada advisory ${ }^{17}$ against its use. Although ibuprofen has been cited as the most common agent used by caregivers to treat musculoskeletal pain, ${ }^{12,13}$ there are concerns that its use as monotherapy may lead to inadequate pain management. ${ }^{6,18}$ Evidence suggests that orally administered morphine ${ }^{13}$ and other opioids are increasingly being prescribed..$^{19}$ However, 
evidence for the oral administration of morphine in acute pain management is limited. ${ }^{20,21}$ Thus, additional studies are needed to address this gap in knowledge and provide a scientific basis for outpatient analgesic choices in children. Our objective was to assess if orally administered morphine is superior to ibuprofen in relieving pain in children with nonoperative fractures.

\section{Methods}

\section{Design and setting}

We conducted a parallel-group, randomized, blinded superiority trial designed to test the hypothesis that orally administered morphine is superior to ibuprofen for outpatient analgesia in children with extremity fractures. We recruited participants from September 2012 to February 2014 from the pediatric emergency department of the Children's Hospital, London Health Sciences Centre, in London, Ontario. This emergency department treats about 40000 children each year, 1900 of whom present with fractures. We received approval for the trial from the Office of Research Ethics on behalf of Western University's Research Ethics Board.

\section{Participants}

We included all children aged 5-17 years who presented to the pediatric emergency department with a nonoperative, radiographically evident extremity fracture sustained within the preceding 24 hours. Our exclusion criteria were known hypersensitivity to either ibuprofen or morphine, chronic use of nonsteroidal anti-inflammatory drugs (NSAIDS) or opioids, associated injuries requiring analgesia, known renal disease, bleeding disorders, poor fluency in English, sleep apnea and pregnancy. The participants consisted of a convenience sample screened consecutively for eligibility for 20 hours/week, between the hours of 1200 and 2300. Written, informed consent and assent were obtained from all patients or their legal guardians.

A trained research assistant assessed eligibility, took participants' informed consent or assent, and performed all other correspondence with participants. The research assistant was invited to assess eligibility after the attending physician's interpretation of the radiograph.

\section{Interventions}

Randomization and concealment of allocation were pharmacy-controlled by use of a computerbased random number generator (www-users. york.ac.uk/ mb55/soft/soft.htm). Eligible participants were randomly assigned in a 1:1 allocation ratio with a stratified block design using a block size of 6 to receive either normal-release morphine (ratio-MORPHINE; Ratiopharm, $0.5 \mathrm{mg} /$ $\mathrm{kg}$, max. $10 \mathrm{mg}$ ) or ibuprofen (Advil; Pfizer Canada, $10 \mathrm{mg} / \mathrm{kg}$, max. $600 \mathrm{mg}$ ) every 6 hours as needed for pain for 24 hours after discharge (max. 4 doses). Concealment of allocation was performed by use of sequentially numbered, opaque sealed envelopes. The interventions were kept in identically appearing, nontranslucent sealed containers. They were prepared by our hospital pharmacy as opaque oral suspensions, identical in appearance, and presented to participants in identical white plastic vials by a research assistant. However, because the interventions differed in taste and consistency, we employed a double-dummy setup whereby each participant was given 4 prepackaged doses consisting of 2 vials, only 1 of which was the active agent. A protocol for unmasking was available on an emergency basis. Participants were counselled to take acetaminophen at a dose of $15 \mathrm{mg} / \mathrm{kg}$ (max. $975 \mathrm{mg}$ ) for breakthrough pain.

Participants were given a data collection form immediately before their discharge from the emergency department, on which they were asked to record pain using the Faces Pain Scale - Revised (FPS-R) immediately before and 30 minutes after each dose. The FPS-R is a 6-item self-report measure to assess the intensity of pain. It has been validated with sound psychometric properties ${ }^{24}$ for use in children at least 4 years of age. ${ }^{25}$ The scale is scored from 0 (no pain) to 5 (maximum amount of pain) by circling the appropriate face on a horizontal axis.

Participants were also asked to record any adverse effects that occurred within 72 hours of the first dose and the number of acetaminophen doses taken for breakthrough pain. We chose 30 minutes because the peak plasma concentration of morphine taken orally is reached at 30 minutes, ${ }^{22}$ and the peak plasma concentration for ibuprofen is reached between 30 and $60 \mathrm{~min}-$ utes. ${ }^{23}$ Participants returned the data forms using a stamped, self-addressed envelope. All participants received a phone call 24 hours after discharge to remind them to return the forms, to enquire about serious complications and to verify compliance. We contacted participants who returned forms with unclear information for clarification. Participants, investigators, the biostatistician and all research assistants were blinded to allocation.

\section{Outcome measures}

Our primary outcome was the difference in pain scale scores before and after the first dose of analgesic. Our secondary outcomes included the type and frequency of adverse effects and the number of participants who required acetaminophen. 


\section{Statistical analysis}

A between-group difference in pain intensity scores of 1 face has been shown to be a minimal clinically important difference. ${ }^{24}$ Assuming a standard deviation of 2 faces, ${ }^{26}$ we needed 63 participants in each group to be able to detect a 1 -face between-group difference at $80 \%$ power with a 2-sided level of significance of 0.05 .

Our analysis was based on a modified intention-to-treat principle and included all participants who took at least 1 dose of the intervention. We used means and standard deviations (SDs), medians and interquartile ranges (IQRs) or frequencies and percentages, as appropriate, to summarize baseline characteristics. We assessed comparisons between participants who did and did not take analgesia using an unpaired $t$ test for continuous variables and a Pearson $\chi^{2}$ test for categorical variables. We used an unpaired $t$ test to assess the primary end point. Similarly, for the second, third and fourth doses, we used unpaired $t$ tests to compare the 2 groups. We used a mixed linear regression model with

Table 1: Characteristics of participants and their fractures, by study drug

\begin{tabular}{|c|c|c|}
\hline Characteristic & $\begin{array}{l}\text { Morphine } \\
n=66\end{array}$ & $\begin{array}{c}\text { Ibuprofen } \\
n=68\end{array}$ \\
\hline Age, yr, mean \pm SD & $10.7 \pm 3.3$ & $10.8 \pm 3.1$ \\
\hline Female sex, no. (\%) & $49(74.2)$ & $43(63.2)$ \\
\hline $\begin{array}{l}\text { Discharge pain score, } \\
\text { median (IQR) }\end{array}$ & $2(1-3)$ & $2(1-3)$ \\
\hline Closed reduction, no. (\%) & $32(48.5)$ & $26(38.2)$ \\
\hline \multicolumn{3}{|l|}{ Type of fracture, no. } \\
\hline Transverse & 63 & 66 \\
\hline Torus & 3 & 2 \\
\hline \multicolumn{3}{|l|}{ Location of fracture } \\
\hline Radius & 30 & 26 \\
\hline Ulna & 1 & 2 \\
\hline Radius + ulna & 13 & 20 \\
\hline Clavicle & 8 & 7 \\
\hline Humerus & 5 & 5 \\
\hline Elbow & 1 & 1 \\
\hline Forearm & 2 & 0 \\
\hline Tibia or fibula & 6 & 7 \\
\hline \multicolumn{3}{|l|}{ Type of immobilization } \\
\hline Circular cast & 48 & 48 \\
\hline Splint & 5 & 12 \\
\hline Sling & 9 & 5 \\
\hline Collar and cuff & 2 & 1 \\
\hline None & 2 & 2 \\
\hline
\end{tabular}

an unstructured covariance matrix to assess the between-group differences across all 4 doses. We used analysis of variance and a test of interaction to perform a prespecified subgroup analysis involving only those patients who underwent closed reduction. We used a Pearson $\chi^{2}$ to evaluate between-group differences in the proportions of participants who required breakthrough analgesia and had adverse effects.

We used the SPSS statistical software package (version 19) for data analysis. We considered $p$ values less than 0.05 to be significant.

\section{Results}

\section{Participants}

Of the 183 participants who underwent randomization, $134(73.2 \%)$ took at least 1 dose of the intervention and were included in our analysis (66 participants from the morphine group and 68 from the ibuprofen group) (Table 1, Figure 1). All of the participants who did not take any of the study drugs reported that they did not feel pain severe enough to require an analgesic. There were no significant differences between participants who did take analgesia and those who did not with respect to age $(10.7 \pm 3.2$ v. $11.5 \pm 3.2, p=0.09)$, sex (42 girls [31\%] v. 18 girls [37\%], $p=0.8$ ), median pain score on discharge (3 [IQR 2-4] v. 3 [IQR 2-4], $p<1.0)$ or number of closed reductions (56 [42\%] v. 20 [41\%], $p=0.45)$.

\section{Primary outcome}

Both morphine and ibuprofen resulted in a decrease in pain scores at each dose administration. The between-group difference in pre-post changes in pain scores was not significant (Table 2).

\section{Secondary outcomes}

Between-group differences for the second, third and fourth doses were not significant (Table 2). We found no evidence that the differences in pain scores changed over time $(p=0.3)$. For each of the 4 doses, tests for heterogeneity were nonsignificant whether or not the participant had a closed reduction ( $p=0.4,0.4,0.6$ and 0.4 , respectively).

There were no significant differences in the percentage of participants requiring acetaminophen for breakthrough pain in the morphine or ibuprofen groups $(17$ [25.7\%] v. 10 [14.7\%], $p=$ 0.1 ). No severe adverse drug reactions (e.g., immune-mediated hypersensitivity) were reported by any of the participants, and there were no deaths. Significantly more participants in the morphine group had adverse effects, the most common of which was drowsiness (more than $1 / 3$ of participants in the morphine group, Table 3 ). 


\section{Interpretation}

In this randomized controlled study involving children with nonoperative fractures, we show that both morphine taken orally and ibuprofen resulted in improved pain scores with no significant difference in analgesic efficacy. However, morphine was associated with a greater frequency of adverse effects.

Concerns surrounding the safety of codeine in children ${ }^{16,17}$ has left a void in the choices of opioid therapy available for moderate to severe pain. As a possible consequence, some evidence suggests that the use of oral morphine is increasing. ${ }^{13}$ However, our results suggest that ibuprofen remains a relatively safe and effective analgesic agent for children who have sustained a nonoperative extremity fracture.

Two studies have investigated the use of morphine to relieve pain in pediatric fractures. In a single-arm trial, $0.5 \mathrm{mg} / \mathrm{kg}$ morphine administered orally decreased pain scores at 30 minutes. ${ }^{20}$ In an observational study comparing morphine administered intravenously with morphine administered orally, intravenous administration $(0.2-0.4 \mathrm{mg} / \mathrm{kg})$ resulted in greater pain reduction as assessed by a 5 -item faces pain scale. ${ }^{27} \mathrm{We}$ found children in the morphine group had significantly more adverse effects. Previous studies have described similar frequencies of nausea, vomiting and drowsiness, ${ }^{28}$ consistent with the expected adverse effects of morphine. ${ }^{29}$

Our finding of a lack of analgesic superiority of morphine over ibuprofen is consistent with several studies involving children with orthopedic injuries. Ibuprofen has been found to be more efficacious than either acetaminophen or codeine, ${ }^{18}$ equivalent to an acetaminophencodeine combination ${ }^{32}$ and equivalent to oxycodone. ${ }^{33}$ In the only study of outpatient analgesia involving children with fractures, ibuprofen was

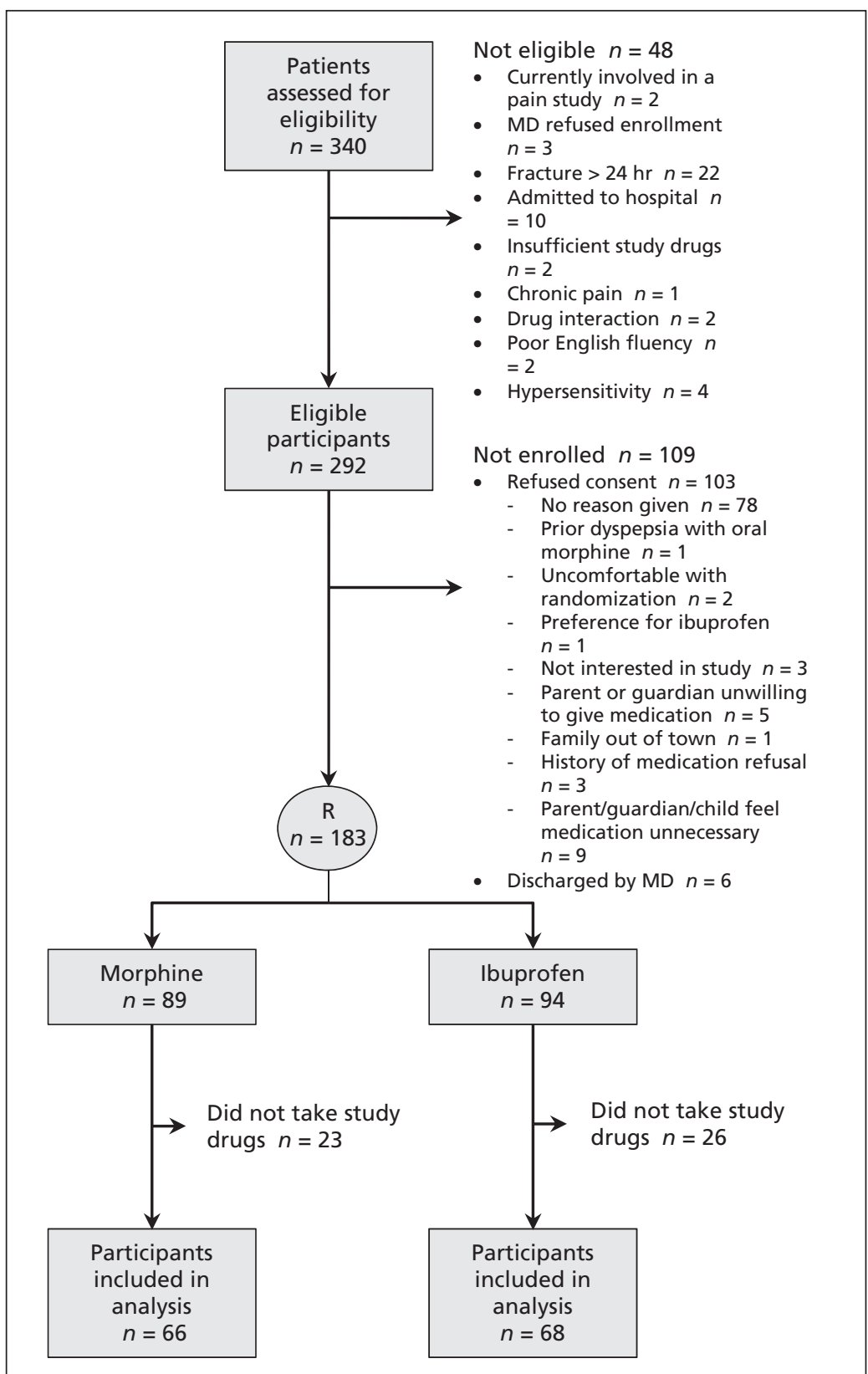

Figure 1: Flow of participants through the trial. $\mathbf{R}=$ randomization.

Table 2: Mean pre-post differences in pain scores* between groups $†$

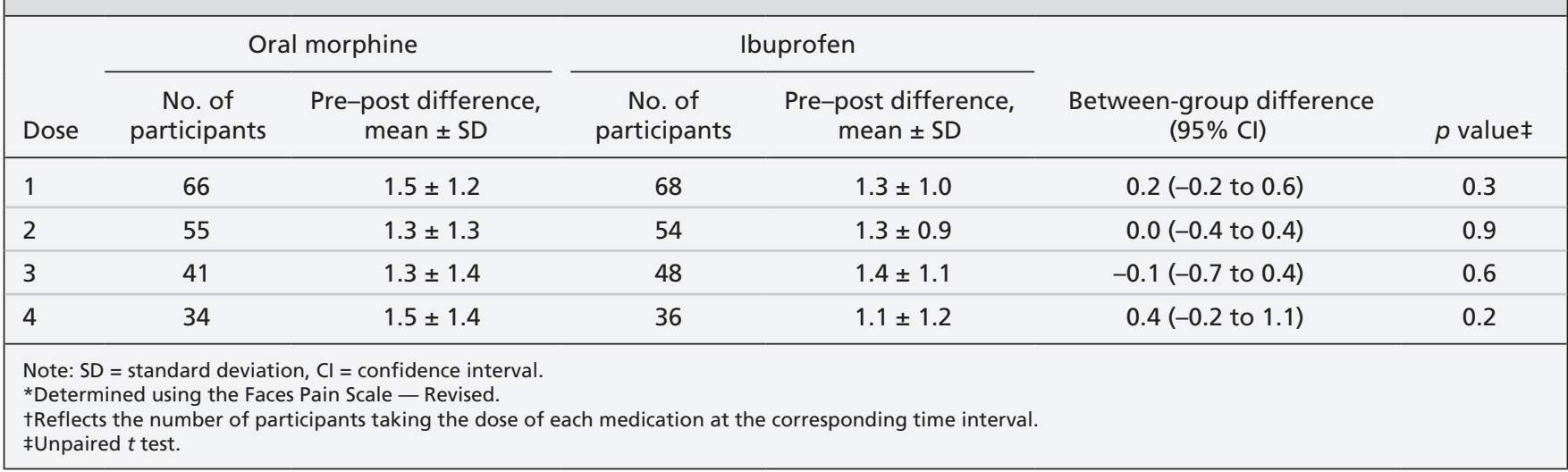


Table 3: Proportion of participants with adverse effects between groups

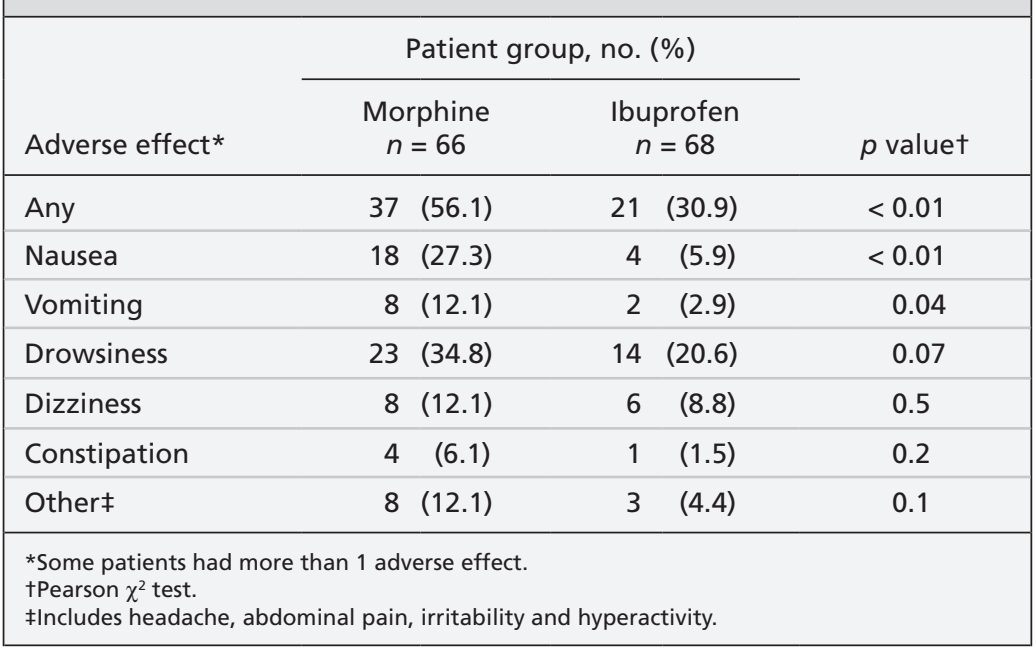

associated with less impairment in functional outcomes and was more tolerable than acetaminophen plus codeine. Studies involving both adults and children with a variety of painful conditions have shown that ibuprofen's efficacy is comparable with or superior to that of opioids. ${ }^{18,28,32,33}$ The possibility of comparable efficacy for musculoskeletal pain between NSAIDs and opioids as drug classes is evidenced by other studies that have shown ketorolac to be superior to morphine ${ }^{34}$ and equivalent to tramadol. ${ }^{35}$ Given ibuprofen's and morphine's similar and inexpensive prices, in addition to these results and ours, ibuprofen should be the initial drug of choice for acutely painful musculoskeletal trauma in children.

\section{Limitations}

To preserve blinding, participants took the intervention no more frequently than every 6 hours. However, the duration of action of normalrelease morphine taken orally is 2 to 4 hours. ${ }^{22}$ Acetaminophen for breakthrough pain may have decreased the preintervention pain scores in the morphine group, providing a more conservative estimate of effect size.

Our study design favoured the pragmatic end of the Pragmatic-Explanatory Continuum Indicator Summary. ${ }^{36}$ Our intent was to determine the effects of analgesia under typical outpatient conditions. However, broad inclusion criteria may have added substantial between-subject variability, thereby decreasing power. We allowed participants to take analgesia on an as-needed basis because analgesic requirements after fracture immobilization are not universal, and fixed dosing may have led to noncompliance ${ }^{12}$ without benefiting short-term functional outcomes. ${ }^{12}$ Although as-needed dosing may have under- mined randomization, there were no significant differences in parameters that may have influenced the response to analgesia when we compared participants who did and did not take the intervention.

The bioavailability of morphine is influenced by renal $^{30}$ and hepatic function. ${ }^{31}$ We did not evaluate these parameters. However, because all of the participants who underwent randomization were children who were otherwise healthy, we surmised that there would be little heterogeneity in pharmacokinetic parameters that could affect our primary outcome.

Finally, our study was a negative trial in that we did not find significant superiority in efficacy of morphine over ibuprofen. We chose to compare morphine against an active comparator primarily because a participant randomly assigned to a placebo may decide to take an analgesic agent if they are in pain. We felt this would contaminate the trial with a cointervention that may be inconsistent with respect to agent, dose and frequency. Although our study was powered to detect a minimal clinically important difference of 1 face on the FPS-R, it was not powered to detect between-group differences in adverse effects, analgesia for breakthrough pain or pain between reduced and nonreduced fractures.

\section{Conclusion}

Both morphine taken orally and ibuprofen showed analgesic efficacy in children with fractures for the first 24 hours after their discharge from the emergency department, and there were no significant differences between the 2 agents. Given that morphine was associated with significantly more adverse effects, we conclude that ibuprofen remains a safe and effective therapy for outpatient management of children's fracture pain. We hope that our results will provide clinicians with a foundation for rational analgesic choices for children with fractures who are discharged from the emergency department. Possible future research includes evaluating the role of single-dose morphine administered orally for breakthrough pain in children, as well as combination therapy of ibuprofen with morphine.

\section{References}

1. Friedland LR, Pancioli AM, Duncan KM. Pediatric emergency department analgesic practice. Pediatr Emerg Care 1997;13:103-6.

2. Todd KH, Ducharme J, Choiniere M, et al. Pain in the emergency department: results of the pain and emergency medicine initiative (PEMI) multicenter study. J Pain 2007;8:460-6.

3. Wilson JE, Pendleton JM. Oligoanalgesia in the emergency department. Am J Emerg Med 1989;7:620-3.

4. Ali S, Chambers AL, Johnson DW. Paediatric pain management practice and policies across Alberta emergency departments. Paediatr Child Health 2014;19:190-4.

5. Brown JC, Klein EJ, Lewis CW, et al. Emergency department 
analgesia for fracture pain. Ann Emerg Med 2003;42:197-205.

6. Ali S, Drendel AL, Janeva Kircher B, et al. Pain management of musculoskeletal injuries in children. Pediatr Emerg Care 2010; 26:518-24, quiz 525-8.

7. Taddio A, McGrath P, Finley A. Effects of early pain experience: the human literature. In: McGrath PJ, Finley GA, editors. Chronic and recurrent pain in children and adolescents. Vol. 13 in Progress in Pain Research and Management. Seattle: IASP Press; 1999. p. $57-74$.

8. Weisman SJ, Bernstein B, Schechter NL. Consequences of inadequate analgesia during painful procedures in children. Arch Pediatr Adolesc Med 1998;152:147-9.

9. Pate JT, Blount RL, Cohen LL, et al. Childhood medical experience and temperament as predictors of adult functioning in medical situations. Child Health Care 1996;25:281-98.

10. Fein JA, Zempsky WT, Cravero JP; Committee on Pediatric Emergency Medicine and Section on Anesthesiology and Pain Medicine, American Academy of Pediatrics. Relief of pain and anxiety in pediatric patients in emergency medical systems. Pediatrics 2012;130:e1391-405.

11. Landin LA. Epidemiology of children's fractures. J Pediatr Orthop B 1997;6:79-83.

12. Drendel AL, Lyon R, Bergholte J, et al. Outpatient pediatric pain management practices for fractures. Pediatr Emerg Care 2006;22:94-9.

13. Kircher J, Drendel AL, Newton AS, et al. Pediatric musculoskeletal pain in the emergency department: A medical record review of practice variation. CJEM 2013;15:1-9.

14. Ciszkowski C, Madadi P, Phillips MS, et al. Codeine, ultrarapidmetabolism genotype, and postoperative death. $N$ Engl J Med 2009;361:827-8

15. Voronov P, Przybylo HJ, Jagannathan N. Apnea in a child after oral codeine: a genetic variant - an ultra-rapid metabolizer. Paediatr Anaesth 2007;17:684-7.

16. Codeine use in certain children after tonsillectomy and/or adenoidectomy: drug safety communication - risk of rare, but lifethreatening adverse events or death. Silver Spring (MD): U.S Food and Drug Administration; 2013. Available: www.fda.gov/ Safety/MedWatch/SafetyInformation/SafetyAlertsforHumanMedicalProducts/ucm315627.htm (2014 Apr. 14).

17. Health Canada. Health Canada's review recommends codeine only be used in patients aged 12 and over. Ottawa: Health Canada; 2013. Available: http://healthycanadians.gc.ca/recall-alert-rappelavis/hc-sc/2013/33915a-eng.php (2014 Apr. 14)

18. Clark E, Plint AC, Correll R, et al. A randomized, controlled trial of acetaminophen, ibuprofen, and codeine for acute pain relief in children with musculoskeletal trauma. Pediatrics 2007; 119:460-7.

19. Lewis ET, Cucciare MA, Trafton JA. What do patients do with unused opioid medications? Clin J Pain 2014;30:654-62.

20. Wille C, Bocquet N, Cojocaru B, et al. Oral morphine administration for children's traumatic pain. Arch Pediatr 2005;12: 248-53.

21. Wille-Ledon C, Chappuy H, Giraud C, et al. Comparison of a morphine and midazolam combination with morphine alone for paediatric displaced fractures: a randomized study. Acta Paediatr 2011;100:e203-7

22. Zernikow B, Michel E, Craig F, et al. Pediatric palliative care: use of opioids for the management of pain. Paediatr Drugs 2009; 11:129-51.

23. Tucci J, Bandiera E, Darwiche R, et al. Paracetamol and ibuprofen for paediatric pain and fever. J Pharm Pract Res 2009; 39:223-5.

24. Hicks CL, von Baeyer CL, Spafford PA, et al. The Faces Pain Scale-Revised: toward a common metric in pediatric pain measurement. Pain 2001;93:173-83.

25. McGrath PJ, Walco GA, Turk DC, et al. Core outcome domains and measures for pediatric acute and chronic/recurrent pain clinical trials: PedIMMPACT recommendations. J Pain 2008;9:771-83.

26. Altman DG, Machin D, Bryant TN, et al., editors. Statistics with confidence: confidence intervals and statistical guidelines. London: Wiley; 2000.

27. Beale JP, Oglesby A, Jones A, et al. Comparison of oral and intravenous morphine following acute injury in children. Eur J Emerg Med 2001;8:271-4.

28. Drendel AL, Gorelick MH, Weisman SJ, et al. A randomized clinical trial of ibuprofen versus acetaminophen with codeine for acute pediatric arm fracture pain. Ann Emerg Med 2009; 54:553-60.

29. Repchinsky C, Welbanks L, Bisson R, editors. Compendium of pharmaceuticals and specialties: the Canadian drug reference for health professionals. Ottawa: Canadian Pharmacists Association; 2002.

30. Osborne R, Joel S, Grebenik K, et al. The pharmacokinetics of morphine and morphine glucuronides in kidney failure. Clin Pharmacol Ther 1993;54:158-67.

31. Hasselström J, Eriksson S, Persson A, et al. The metabolism and bioavailability of morphine in patients with severe liver cirrhosis. Br J Clin Pharmacol 1990;29:289-97.

32. Friday JH, Kanegaye JT, McCaslin I, et al. Ibuprofen provides analgesia equivalent to acetaminophen-codeine in the treatment of acute pain in children with extremity injuries: a randomized clinical trial. Acad Emerg Med 2009;16:711-6.

33. Koller DM, Myers AB, Lorenz D, et al. Effectiveness of oxycodone, ibuprofen, or the combination in the initial management of orthopedic injury-related pain in children. Pediatr Emerg Care 2007;23:627-33

34. Rainer TH, Jacobs P, Ng YC, et al. Cost effectiveness analysis of intravenous ketorolac and morphine for treating pain after limb injury: double blind randomised controlled trial. $B M J$ 2000;321:1247-51.

35. Neri E, Maestro A, Minen F, et al. Sublingual ketorolac versus sublingual tramadol for moderate to severe post-traumatic bone pain in children: a double-blind, randomised, controlled trial. Arch Dis Child 2013;98:721-4.

36. Thorpe KE, Zwarenstein M, Oxman AD, et al. A pragmaticexplanatory continuum indicator summary (PRECIS): a tool to help trial designers. J Clin Epidemiol 2009;62:464-75.

Affiliations: Division of Emergency Medicine (Poonai, Bhullar, Lin, Papini, Mainprize, Howard, Teefy, Bale, Langford, Lim, Stitt), London Health Sciences Centre; Department of Paediatrics (Poonai, Lim), Schulich School of Medicine and Dentistry, Western University; and Department of Paediatrics (Rieder), Children's Hospital of Western Ontario, London, Ont.; Department of Pediatrics (Ali), University of Alberta; and Women and Children's Health Research Institute (Ali), Edmonton, Alta.

Contributors: Naveen Poonai is the primary investigator and was responsible for designing the study, interpreting and analyzing the data and writing the manuscript. Gina Bhullar was responsible for data entry and writing the manuscript. Kangrui Lin, Adam Papini, Jocelyn Howard, Michelle Bale, David Mainprize, John Teefy and Cindy Langford were responsible for writing the manuscript. Samina Ali and Rod Lim revised the manuscript for important intellectual content. Larry Stitt performed the statistical analysis and revised the manuscript for important intellectual content. Michael Rieder assisted with the study design and drafting and revising of the article. All of the authors approved the final version of the manuscript submitted for publication and have agreed to act as gaurantors of the work.

Funding: The authors state no conflict of interest and have received no payment in preparation of this manuscript. This study is funded from a Schulich Research Opportunities Grant from Western University.

Data sharing: Data available on request to the corresponding author. Data can be accessed after a signed data transfer agreement is in place. Data will be transferred electronically through a secure network in a password-protected file. 